\title{
XXXII. On Mr. G. F. Fitzgerald's Paper "On the mechanical theory of Crookes's force"
}

\section{Osborne Reynolds F.R.S.}

To cite this article: Osborne Reynolds F.R.S. (1879) XXXII. On Mr. G. F. Fitzgerald's Paper "On the mechanical theory of Crookes's force", Philosophical Magazine Series 5, 7:42, 179-181, DOI: $10.1080 / 14786447908639589$

To link to this article: http://dx.doi.org/10.1080/14786447908639589

曲 Published online: 13 May 2009.

Submit your article to this journal $\lceil\pi$

Џ Article views: 2

Q View related articles $₫$ 
XXXII. On Mr. G. F. Fitzgerald's Paper "On the Mechanical Theory of Crookes's Force." By OsboRNe Reynolds, F.R.S.**

$\mathrm{M}$

R. FITZGERALD appears to have overlooked the fact that my paper in the Proceedings of the Royal Society, 1874, "On the Surface Forces caused by Evaporation and Condensation," was published more than a year before Mr. Crookes published any account of the radiometer; otherwise he certainly would not have fallen into the error of supposing that I had concluded that the motion of the arms of the radiometer was mainly due to evaporation and condensation. That such actions cannot explain continuous motion is at once obvious. But then Mr. Fitzgerald fails to notice that on the first page of my paper an experiment is described which proves this very point; and he also fails to notice that all the phenomena I have considered in any way due to evaporation and condensation were essentially intermittent.

It would appear that Mr. Fitzgerald has not read my paper; for after stating that the method by which I "tried to show that a surface, when communicating heat to gas, is subject to an increased pressure is open to the overwhelming objection that this increased pressure would be almost instantaneously transmitted to all parts of the enclosed gas," he devotes some fourteen pages to the attempt to prove the very same thing.

To point out these errors in Mr. Fitzgerald's statements constituted my main object in writing this note ; but I would say a few words on the subject in question and Mr. Fitzgerald's treatment of it.

Mr. Fitzgerald bases his theory on Mr. Stoney's view that the phenomena of the radiometer are to be explained by the fundamental assumption "that when two surfaces at different temperatures are in presence of one another with a gas between them, there exists a force ter ding to separate them." Assuming that it is here meant that the gas should surround the surfaces and not merely exist between them, it may appear at first sight as though this assumption would explain the phenomena; but on closer examination it will appear, as I have previously pointed out, that this is not the case. Under such conditions as are assumed the experiments show that the force would not tend to separate the surfaces, but such forces as there might be would impel both surfaces in the same direction-showing that the force does not act between the two surfaces, but between each surface and the gas which surrounds

* Communicated by the Author. 
it-and that the force does not arise from the difference in temperature in the two opposite plates, but from the difference in temperature of the two surfaces of the same plate.

It appears, then, that such a separating force as that assumed by Mr. Fitzgerald would not explain the phenomena in question, and therefore that these phenomena afford us no ground for assuming the existence of such a force. Any reason there may be for assuming such a force must therefore come out of some hypothesis as to the constitution of gas ; and in this respect the result of Mr. Fitzgerald's investigation is not very conclusive.

Adopting the hypothesis of Clausius, Mr. Fitzgerald's reasoning leads him to the conclusion that there is no such separating force (see the bottom of page 22). Instead, however, of accepting the conclusion, Mr. Fitzgerald concludes that Clausius is wrong :- "It seems certain that the hypothetical distribution Clansius assumed is not at all adequate to represent the actual one." He then proceeds to modify the expression derived from Clausius' hypothesis so as to make it yield the force for which he is looking; but he attempts no explanation or examination of the physical meaning of such a modification; so that admitting, as I have pointed out, that we have no experimental evidence of such a separating force, Mr. Fitzgerald's investigation clearly affords us none, but, on the other hand, shows either that Clausius is wrong or that there is no such force.

Had Mr. Fitzgerald been true to his mathematics, had he accepted the conclusion that there is no such separating force as he has assumed, and then examined the physical meaning of the modifications of the expressions which he has introduced, I venture to say that he would have found that his modifications of Clausius' hypothesis, on the assumption that the direction of flow of heat is everywhere the same, would correspond with the true expressions of Clausius' hypothesis when there is divergence in the directions along which heat is flowing.

This divergence turns out to be an essential condition in order that there may be force such as that which causes motion in the arms of the radiometer. And since the pressure in the direction of flow is greater or less than the mean pressure, according as the lines of flow diverge or converge, the pressure will be greater against the hot side of a plate and less against the cold side.

When I first suggested that there would be an inequality of gaseous pressure arising from a communication of heat, I had not realized that, besides depending on the quantity of 
heat communicated, the inequality would depend on the divergence of the lines of flow-although my explanation, so far as it went, was quite consistent with such a necessity.

The importance of this divergence became clearer to $m e$ in November 1877; and I had no sooner recognized it than I perceived a general connexion between the phenomena in question and other phenomena of gases, particularly that of transpiration, or diffusion through porous plugs. I did not then publish any account of the theoretical investigation, because the theory indicated the existence of other phenomena beyond those already known, and I wished to verify these indications of the theory by experiment.

These experiments have occupied considerable time; but they are now completed, and their result is (1) to verify the theoretical revelations as to the existence of a class of very marked and important phenomena which were, so far as I know, previously unsuspected, (2) to establish certain general laws which apply equally to the phenomena of transpiration and those of the radiometer, and (3) to afford an absolute proof that gas possesses dimensional structure (i.e. that it is not a continuous plenum), the results of the experiments agreeing with those deduced from the theory in the most definite manner. A paper containing an account of both the theoretical and experimental investigations has been forwarded to the Royal Society.

January $28,1879$.

XXXIII. The Theory of Binaural Audition. A Contribution to the Theory of Sound. By ANTon Stennhauser *.

[Plate IX.]

INTRODUCTION.

THE theory of Audition may be divided into two portionsthat of Monaural Audition, or of hearing with one ear, and that of Binaural Audition, or of hearing with both ears. The former, already treated of in every textbook of Physics, is concerned with explaining the arrangement of the human ear, the function of its separate parts, and, lastly, how the ear is instrumental in the faculty of hearing. The second branch of the subject, which has never, to my knowledge, been yet developed $\dagger$, has to discuss the general question of hearing,

* Translated and communicated by Prof. Silvanus P. Thompson.

$\dagger[$ For the literature of the subject see:-

Luca, A.-Virchow, Archiv, xxv. 1862: "Zur Physiologie und Pathologie des Gehörorganes."

Rayleigh, Lord.-Proc. Mus. Assoc. 1875-76: "On our Perception of the Direction of a Source of Sound."

Thompson, S. P.-Rep. Brit. Assoc. 1877: "On Binaural Audition, Phil. Mag. S. 5. Vol. 7. No. 42. March 1879. 